\title{
Effect of environmental variability and spawner characteristics on the recruitment of Baltic herring Clupea harengus populations
}

\author{
Massimiliano Cardinale ${ }^{1, *}$, Christian Möllmann², Valerio Bartolino ${ }^{3}$, \\ Michele Casini ${ }^{1}$, Georgs Kornilovs ${ }^{4}$, Tiit Raid ${ }^{5}$, Piotr Margonski ${ }^{6}$, Anna Grzyb ${ }^{6}$, \\ Jari Raitaniemi $^{7}$, Tomas Gröhsler ${ }^{8}$, Juha Flinkman ${ }^{9}$ \\ ${ }^{1}$ Institute of Marine Research, Swedish Board of Fisheries, PO Box 4, 45321 Lysekil, Sweden \\ ${ }^{2}$ Institute for Hydrobiology and Fisheries Science, University of Hamburg, Grosse Elbstrasse 133, 22767 Hamburg, Germany \\ ${ }^{3}$ Department of Animal and Human Biology, University of Rome La Sapienza, Viale dell'universita 32, 00185 Rome, Italy \\ ${ }^{4}$ Latvian Fish Resources Agency, Daugavgrivas Str. 8, 1048 Riga, Latvia \\ ${ }^{5}$ European Commission Joint Research Centre (JRC), Institute for the Protection and Security of the Citizen, \\ Maritime Affairs Unit, 21027 Ispra, Italy \\ ${ }^{6}$ Sea Fisheries Institute, ul. Kollataja 1, 81-332 Gdynia, Poland \\ ${ }^{7}$ Finnish Game and Fisheries Research Institute, Turku Game and Fisheries Research, Itäinen Pitkäkatu 3, \\ 20520 Turku, Finland \\ ${ }^{8}$ Federal Research Centre for Fisheries, Institute for Baltic Sea Fisheries, Alter Hafen Süd 2, 18069 Rostock, Germany \\ ${ }^{9}$ Finnish Institute of Marine Research, PO Box 2, 00561 Helsinki, Finland
}

\begin{abstract}
We analyzed recruitment-environment relationships for 5 distinct Baltic Sea herring stocks inhabiting the areas of the Western Baltic (WBH), the Main Basin (MBH), the Gulf of Riga $(\mathrm{GRH})$, the Bothnian Sea (BSH) and the Bothnian Bay (BBH). A number of hydro-climatic and biological predictors were tested for their effect on recruitment. Temperature was determined to be an important predictor for 3 of the stocks (MBH, GRH and BSH). However, spawning stock biomass was the major factor explaining recruitment for GRH and weight-at-age of the spawners was an important predictor of $\mathrm{MBH}$ recruitment. For 2 out of 4 stocks for which complete zooplankton data were available (BSH and $\mathrm{MBH}$ ), food supply was also a significant predictor, suggesting that changes in climate and/or food web structure may indirectly affect herring recruitment via prey availability for the recruits or spawners. Our results emphasize both similarities and differences in the main regulators of recruitment dynamics for the 5 stocks that should be taken into consideration in the development of area-specific management strategies throughout the Baltic Sea basin.
\end{abstract}

KEY WORDS: Baltic Sea herring $\cdot$ Recruitment $\cdot$ Spawner effects $\cdot$ Climate $\cdot$ Spatial differences

\section{INTRODUCTION}

The Atlantic herring Clupea harengus is a key species in many temperate marine ecosystems (Blaxter \& Hunter 1982). It typically represents one of the main food items for piscivorous top predators like cod Gadus morhua (Link et al. 2008) and in turn feeds upon the lower trophic levels (Blaxter \& Hunter 1982). The Baltic Sea hosts a number of different herring populations
(ICES 2007), which are of considerable economic importance for the bordering countries. These populations inhabit local ecosystems with different abiotic and biotic conditions. The salinity gradient is among the most prominent hydrological features, ranging from almost marine conditions in the Western Baltic to nearly fresh water conditions in the northern areas of the Bothnian Bay. Also, temperature differs strongly between southern and northern Baltic areas. As a result, the 
structure of the local ecosystems varies, as does the structure of the zooplankton community (ICES 2008).

Besides environmental gradients, the state of the different herring populations in the Baltic Sea is also affected by area-specific exploitation patterns influencing the size of the spawning stock (ICES 2007). A recent meta-analysis on fish recruitment processes revealed herring recruitment to be related to spawning stock biomass (SSB) for the stocks in the Baltic main basin, the Gulf of Riga and the Bothnian Sea (Cardinale et al. 2008). However, the large residuals around the stock-recruitment relationships indicated that other factors are involved in determining recruitment strength. No stock-recruitment relationship was found for the herring stocks in the Bothnian Bay and Western Baltic (Cardinale et al. 2008). Therefore, other biotic and abiotic processes may be important in determining herring year-class strength in these areas.

Several recent studies have focused on the effect of climate variability on fish recruitment dynamics and environmental factors have been modelled to explain recruitment variability in a number of fish stocks (e.g. Williams \& Quinn 2000, Fiksen \& Slotte 2002, Stige et al. 2006). Specifically, in the Baltic Sea region, atmospheric forcing has changed considerably, especially at the end of the 1980s, leading to warmer and less saline conditions affecting all trophic levels of the ecosystem (Alheit et al. 2005). Zooplankton has experienced pronounced changes that have been related to both hydrological variations (Möllmann et al. 2000) and alterations at the upper trophic levels (Casini et al. 2008, 2009). The direct and indirect effects of climate change on several features of Baltic fish stocks have also been intensively studied, but for herring only the effect on growth has been investigated during the last decade (Cardinale \& Arrhenius 2000, Möllmann et al. 2005, Casini et al. 2006). Analyses of recruitment processes of Baltic fish stocks have been mainly directed to cod and sprat Sprattus sprattus (Köster et al. 2003, MacKenzie \& Köster et al. 2005).

Here we investigated the direct and indirect effects of environmental variability as well as the characteristics of spawners on the recruitment dynamic of Baltic herring stocks.

\section{MATERIALS AND METHODS}

Baltic Sea herring stocks. We considered 5 Baltic herring stocks in our analyses: Western Baltic (WBH), Central Baltic (Main Basin; MBH), Gulf of Riga (GRH), Bothnian Sea (BSH) and Bothnian Bay (BBH) herring (Fig. 1). We used data on SSB and recruitment at age 1 for all the stocks (except for $\mathrm{WBH}$, where recruitment at age 0 was used as it is the first estimated age class for this stock) as available from official ICES sources (ICES 2007). The considered herring stocks are distributed in the various sub-systems of the Baltic Sea (Fig. 1) and hence encounter different environments with respect to topography, hydrography and food supply (Aro 1989). Spawning location and spawning period for each stock are summarized in Table 1.

Hydro-climatic and biological data. We selected a number of abiotic predictors for herring recruitment on the basis of known ecological, biological and physiological processes, as well as data availability. We used the Baltic Sea Index (BSI) to characterize the largescale atmospheric-climatic conditions of the Baltic Sea. The BSI is closely related to the North Atlantic Oscillation index (Hurrell 1995), but directly reflects the impact of climate variability on local oceanographic processes in the central Baltic Sea (Lehmann et al. 2002). The BSI is defined as the difference in normalized sea level pressure anomalies between the positions $53^{\circ} 30^{\prime} \mathrm{N}, 14^{\circ} 30^{\prime} \mathrm{E}$ (Szczecin, Poland) and $59^{\circ} 30^{\prime} \mathrm{N}, 10^{\circ} 30^{\prime} \mathrm{E}$ (Oslo, Norway). Positive values of

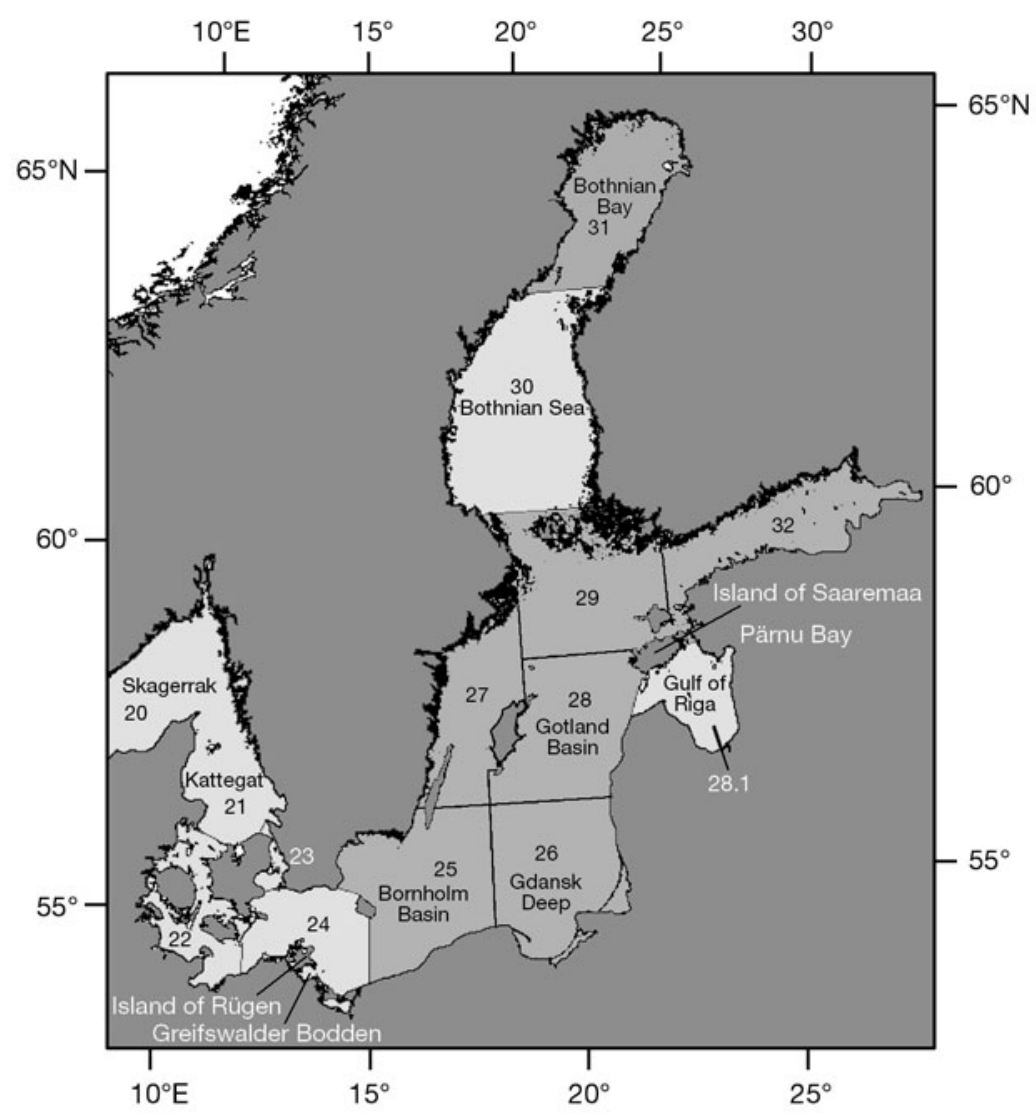

Fig. 1. Study area with ICES Sub-divisions and stock distribution: Western Baltic (ICES SD 20-24), Central Baltic (ICES SD 25-29 \& 32 excl. Gulf of Riga), Gulf of Riga (ICES SD 28.1), Bothnian Sea (ICES SD 30) and Bothnian Bay (ICES SD 31) 
Table 1. Clupea harengus. Spawning location and spawning period for each Baltic herring stock: Western Baltic (WBH), the Main Basin (MBH), the Gulf of Riga (GRH), the Bothnian Sea (BSH) and the Bothnian Bay (BBH)

\begin{tabular}{|llll|}
\hline Stock & \multicolumn{1}{c}{ Spawning location } & Spawning time & Reference \\
\hline WBH & Greifswalder Bodden; Island of Rügen in SD 24 & January-March & Parmanne et al. (1994) \\
MBH & Between 0.5-5.5 m in SD 25-29 \& 32 excl. 28.1 & April-June & Rajasilta et al. (1989) \\
GRH & Gulf of Riga, Pärnu Bay; Saaremaa Island in SD 28.1 & April-June & Kornilovs (1993) \\
BSH & Finnish west coast and the Swedish east coast in SD 30 & May-July & Aro (1989) \\
BBH & Finnish west coast and the Swedish east coast in SD 31 & May-July & Aro (1989) \\
\hline
\end{tabular}

the index correspond to approximately westerly winds over the Baltic and higher temperatures, whereas a negative index corresponds more to easterly winds and lower temperatures (Lehmann et al. 2002). In accordance with the NAO, we used the average of the BSI between December, January and February, representing the period largely determining the abiotic conditions in the following spring growing season (Hurrell 1995). We used mean monthly temperature data (sea surface) from certain months to characterize the thermal conditions at peak spawning time (Aro 1989), i.e. February for WBH, May for $\mathrm{MBH}$ and $\mathrm{GRH}$, and June for $\mathrm{BSH}$ and $\mathrm{BBH}$. Furthermore, we used the mean temperature in August to characterize the first growth period of the young-of-the-year for $\mathrm{MBH}$. We used salinity in February as a variable potentially influencing recruitment for $\mathrm{WBH}$ and $\mathrm{MBH}$, namely surface and deepwater salinity, respectively. We used salinity as a predictor only in the southernmost areas because strongly influenced by variations in water inflows from the North Sea.

As an effect of the characteristics of the spawners, in addition to SSB, we used average individual weights at age $3+\left(\mathrm{WAA}_{3+}\right)$ as a proxy for condition of the adult (spawning) portion of the stocks. Because a truncated stock structure can have negative effects on recruitment success (Marshall et al. 1998), we used the biomass of ages 5 and older $\left(\mathrm{BIOM}_{5+}\right)$ as additional indicator of potential spawners' effects.

The Latvian Fish Resources Agency (LatFRA) provided data on the density (biomass per $\mathrm{m}^{3}$ ) of the major zooplankton species in the Gotland Basin (central Baltic Sea, i.e. the copepods Pseudocalanus acuspes, Temora longicornis, Acartia spp.) collected in May. Details on sampling procedure and plankton identification are described in Kornilovs et al. (2001). The Finnish Institute of Marine Research (FIMR) provided data on the density (abundance per $\mathrm{m}^{3}$ ) of the major zooplankton species in the Bothnian Bay and Bothnian Sea (i.e. the copepods Eurytemora affinis and Acartia spp., and the cladoceran Bosmina longispina) collected in August.

Finally we also explored predation mortality of herring recruitment (age 1) due to predation by cod as a predictor for $\mathrm{MBH}$ recruitment (ICES 2008). Data sources for all predictors used in the analysis are indicated in Table 2.

Statistical analysis of recruitment-environment relationships. The relationship between recruitment ( $\mathrm{R}_{i}$ number of 0 or $1 \mathrm{yr}$ old fish, depending on the stock) and abiotic-biotic factors was analysed with generalized additive models (GAMs). The following additive formulation was used:

$$
R=a+s\left(V_{i}\right)+\ldots+s\left(V_{n}\right)+\varepsilon
$$

where $a$ is the intercept, $s$ the thin plate smoothing spline function (Wood 2003), $V_{i} \ldots V_{n}$ the predictors and $\varepsilon$ the random error.

As predictors, we used abiotic and biotic factors selected a priori on the basis of known ecological, biological and physiological mechanisms (Table 2). To avoid collinearity, we only used predictors that correlated with each other by $<0.70$ (Heinänen et al. 2008), retaining the one that explains the largest part of the variance. First, we included all the hypothesized predictors in the model and then applied a backward stepwise regression based on statistical significance and generalized cross validation (GCV; Wood 2004) information criterion to find the best possible set of predictors. The least significant variable was excluded at each step of the backward stepwise regression. The GCV criterion allows an optimal trade off between the amount of deviance explained by the model and the model complexity measured through the equivalent degrees of freedom. Thus, the selection of smoothing parameters of each single term was done on the measure of the global GCV for the model, in a balance between fitting and smoothing the data. Further, stepwise selected predictors in the best model were screened using the ecological criterion (see Cardinale \& Svedäng 2004 and Casini et al. 2006 for a use of the ecological criterion in model selection). The ecological criterion implies that the shape of the relationship of certain predictors cannot be accepted, although they are statistically significant, because of a lacking ecological basis (Dippner \& Ottersen 2001). For example, there is no ecological basis for zooplankton to negatively affect recruitment (i.e. more zooplankton, lower recruitment). Thus, if the response curve 
was not ecologically interpretable, the variable was removed and the backward selection was continued (see also Heinänen et al. 2008). The final model for each stock was hence selected based on the simultaneous satisfaction of the following: parsimonious principle (the largest amount of deviance explained with the minimum number of predictors and the lowest degrees of freedom), statistical significance $(p<0.05)$ of the predictors and ecological criterion (meaningful ecological relationships).

In order to simplify the interpretation of the results, we limited the maximum degrees of freedom acceptable for each term of the GAM (i.e. $k=3$ ). When the final selected additive model included both predictors related to spawners ( $\mathrm{SSB}, \mathrm{BIOM}_{5+}$ or $\mathrm{WAA}_{3+}$ ) and sea surface tem- perature (SST), their interaction was also tested. Assuming non-additivity is a reflection of the hypothesis that the effect of temperature on recruitment can change in relation to the biological characteristics of the adult stock, and vice-versa, as demonstrated for the stock of North Sea cod (O'Brien et al. 2000). A tensor product smoothing function was adopted to model the interaction of predictors measured in different units. It is an efficient solution when very different degrees of smoothness are required for different covariates (Wood 2006). After reviewing the diagnostic partial residuals plots (Hastie \& Tibshirani 1990, Venables \& Ripley 1994), the gamma error distribution with a log link function was used for all models. Residuals were analysed to test for departure

Table 2. Clupea harengus. Data sources for the predictors used in the recruitment analysis: Western Baltic (WBH), Central Baltic $(\mathrm{MBH})$, Gulf of Riga (GRH), Bothnian Sea (BSH) and Bothnian Bay (BBH). LatFRA = Latvian Fisheries Research Agency; FIMR $=$ Finnish Institute of Marine Research

\begin{tabular}{|c|c|c|c|c|}
\hline Stock area & Stock & Variable & Acronym & Reference \\
\hline ICES SD 20-24 & WBH & Spawning stock biomass & SSB & ICES (2006a) \\
\hline ICES SD 25-29 \& 32 excl. 28.1 & $\mathrm{MBH}$ & Spawning stock biomass & SSB & ICES (2006b) \\
\hline Gulf of Riga ICES SD 28.1 & GRH & Spawning stock biomass & SSB & ICES (2006b) \\
\hline ICES SD 30 & $\mathrm{BSH}$ & Spawning stock biomass & SSB & ICES (2006b) \\
\hline ICES SD 31 & $\mathrm{BBH}$ & Spawning stock biomass & SSB & ICES (2006b) \\
\hline ICES SD $20-24$ & WBH & Recruitment at age 0 & R0 & $\operatorname{ICES}(2006 a)$ \\
\hline ICES SD 25-29 \& 32 excl. 28.1 & $\mathrm{MBH}$ & Recruitment age at 1 & $\mathrm{R} 1$ & ICES (2006b) \\
\hline Gulf of Riga ICES SD 28.1 & GRH & Recruitment age at 1 & $\mathrm{R} 1$ & ICES (2006b) \\
\hline ICES SD 30 & $\mathrm{BSH}$ & Recruitment age at 1 & $\mathrm{R} 1$ & ICES (2006b) \\
\hline ICES SD 31 & $\mathrm{BBH}$ & Recruitment age at 1 & $\mathrm{R} 1$ & ICES (2006b) \\
\hline ICES SD 20-24 & $\mathrm{WBH}$ & Biomass ages $5+$ & $\mathrm{BIOM}_{5+}$ & ICES (2006a) \\
\hline ICES SD 20-24 & $\mathrm{WBH}$ & Weight at age $3+$ & $\mathrm{WAA}_{3+}$ & ICES (2006a) \\
\hline ICES SD 20-24 & WBH & Sea Surface Salinity February & SAL2 & www.smhi.se \\
\hline ICES SD $20-24$ & WBH & Sea Surface Temperature February & SST2 & www.smhi.se \\
\hline ICES SD 25-29 \& 32 excl. 28.1 & $\mathrm{MBH}$ & Biomass ages $5+$ & $\mathrm{BIOM}_{5+}$ & ICES (2006b) \\
\hline ICES SD 25-29 \& 32 excl. 28.1 & $\mathrm{MBH}$ & Weight at age $3+$ & $\mathrm{WAA}_{3+}$ & ICES (2006b) \\
\hline ICES SD 25-29 \& 32 excl. 28.1 & $\mathrm{MBH}$ & Acartia spp. biomass & $\mathrm{ACA}$ & LatFRA \\
\hline ICES SD 25-29 \& 32 excl. 28.1 & $\mathrm{MBH}$ & Temora longicornis biomass & TEM & LatFRA \\
\hline ICES SD 25-29 \& 32 excl. 28.1 & $\mathrm{MBH}$ & Sea Surface Salinity May & SAL5 & www.smhi.se \\
\hline ICES SD 25-29 \& 32 excl. 28.1 & $\mathrm{MBH}$ & Deep Water Salinity May & SALD5 & www.smhi.se \\
\hline ICES SD 25-29 \& 32 excl. 28.1 & $\mathrm{MBH}$ & Sea Surface Temperature May & SST5 & LatFRA \\
\hline ICES SD 25-29 \& 32 excl. 28.1 & $\mathrm{MBH}$ & Sea Surface Temperature August & SST8 & LatFRA \\
\hline ICES SD $25-29 \& 32$ excl. 28.1 & $\mathrm{MBH}$ & Pseudocalanus acuspes biomass & PSE & LatFRA \\
\hline ICES SD 25-29 \& 32 excl. 28.1 & $\mathrm{MBH}$ & Predation mortality by cod at age 0 & $\mathrm{PM}$ & ICES (2007) \\
\hline Gulf of Riga ICES SD 28.1 & GRH & Biomass ages $5+$ & $\mathrm{BIOM}_{5+}$ & ICES (2006b) \\
\hline Gulf of Riga ICES SD 28.1 & GRH & Weight at age $2+$ & $\mathrm{WAA}_{3+}$ & ICES (2006b) \\
\hline Gulf of Riga ICES SD 28.1 & GRH & Acartia spp. biomass & $\mathrm{ACA}$ & LatFRA \\
\hline Gulf of Riga ICES SD 28.1 & GRH & Eurytemora affinis biomass & EUR & LatFRA \\
\hline Gulf of Riga ICES SD 28.1 & GRH & Sea Surface Temperature May & SST5 & LatFRA \\
\hline ICES SD 30 & $\mathrm{BSH}$ & Biomass ages $5+$ & $\mathrm{BIOM}_{5+}$ & ICES (2006b) \\
\hline ICES SD 30 & $\mathrm{BSH}$ & Weight at age $3+$ & $\mathrm{WAA}_{3+}$ & ICES (2006b) \\
\hline ICES SD 30 & $\mathrm{BSH}$ & Sea Surface Temperature June & SST6 & FIMR \\
\hline ICES SD 30 & $\mathrm{BSH}$ & Acartia spp. biomass & $\mathrm{ACA}$ & FIMR \\
\hline ICES SD 30 & $\mathrm{BSH}$ & Bosmina spp. biomass & BOS & FIMR \\
\hline ICES SD 30 & $\mathrm{BSH}$ & Eurytemora affinis biomass & EUR & FIMR \\
\hline ICES SD 31 & $\mathrm{BBH}$ & Biomass ages $5+$ & $\mathrm{BIOM}_{5+}$ & ICES (2006b) \\
\hline ICES SD 31 & $\mathrm{BBH}$ & Weight at age $3+$ & $\mathrm{WAA}_{3+}$ & ICES (2006b) \\
\hline ICES SD 31 & $\mathrm{BBH}$ & Sea Surface Temperature June & SST6 & FIMR \\
\hline ICES SD 31 & $\mathrm{BBH}$ & Bosmina spp. biomass & BOS & FIMR \\
\hline ICES SD 31 & $\mathrm{BBH}$ & Eurytemora affinis biomass & EUR & FIMR \\
\hline ICES SD 20-32 & All stocks & Baltic Sea Index & BSI & Lehmann et al. (2002) \\
\hline
\end{tabular}


from the model assumptions or other anomalies in the data or in the model fit using graphical methods (Cleveland 1993). Residuals were also plotted against the predicted values to inspect for their homogeneity and violation from normality assumption. The temporal autocorrelations in the data set were addressed after we analysed the autocorrelation of the model residuals. This method, suggested by Brockwell \& Davis (1996), examines the temporal autocorrelation in the model residuals using the autocorrelation function (acf) in R. It is considered particularly appropriate for models with an explicit temporal effect (the year effect in our model). The analysis was performed using the mgcv library of R (www. r-project.org). The level of significance was set to $5 \%$ for all the statistical tests used in this study.

\section{RESULTS}

\section{Temporal trends in Baltic herring stocks}

Stock and recruitment data for WBH were available only from 1991 and onwards (Fig. 2a). SSB declined since the early $1990 \mathrm{~s}$, while recruitment fluctuated and was low since the beginning of the 2000s. In MBH, SSB and recruitment displayed a continuously decreasing trend since the mid 1970s, with a slight increase during the last few years (Fig. 2b). In contrast, SSB and recruitment of GRH increased sharply throughout the 1990s, a pattern observed as well for BSH (Fig. 2c,d). $\mathrm{BBH}$ experienced decreasing biomass since the early 1990s, with an increase during the last years, whereas recruitment was very variable with a general slight increase in recent years (Fig. 2e).

All herring stocks recently showed decreasing individual weights, except in $\mathrm{WBH}$, for which decreasing stock biomass was accompanied by stable individual weights (Fig. 3a). While $\mathrm{MBH}$ and $\mathrm{BBH}$ individual weight decreased with decreasing stock biomass, GRH and $\mathrm{BSH}$ individual weights decreased in parallel to a biomass increase of the stock. The biomass of ages 5+ decreased continuously during the whole observed period in $\mathrm{MBH}$ and $\mathrm{BBH}$, while in $\mathrm{WBH}$ it first dropped and then increased (Fig. 3b). BSH and GRH, on the contrary, displayed an increase in biomass of the $5+$ group in the latest years.

\section{Temporal trends in the abiotic and biotic environment}

The Baltic Sea Index (BSI), as an index for the atmospheric forcing over the whole Baltic Sea area, showed a switch from mainly negative values until the late 1980s to mainly positive values afterwards (Fig. 4a).
This change in the atmospheric forcing to more westerly winds, causing milder winter and spring conditions, is reflected in increased May temperatures in the Main Basin and the Gulf of Riga (Fig. 4c). Increased temperatures in the last decade have also been observed in August in the Main Basin, while June tem-
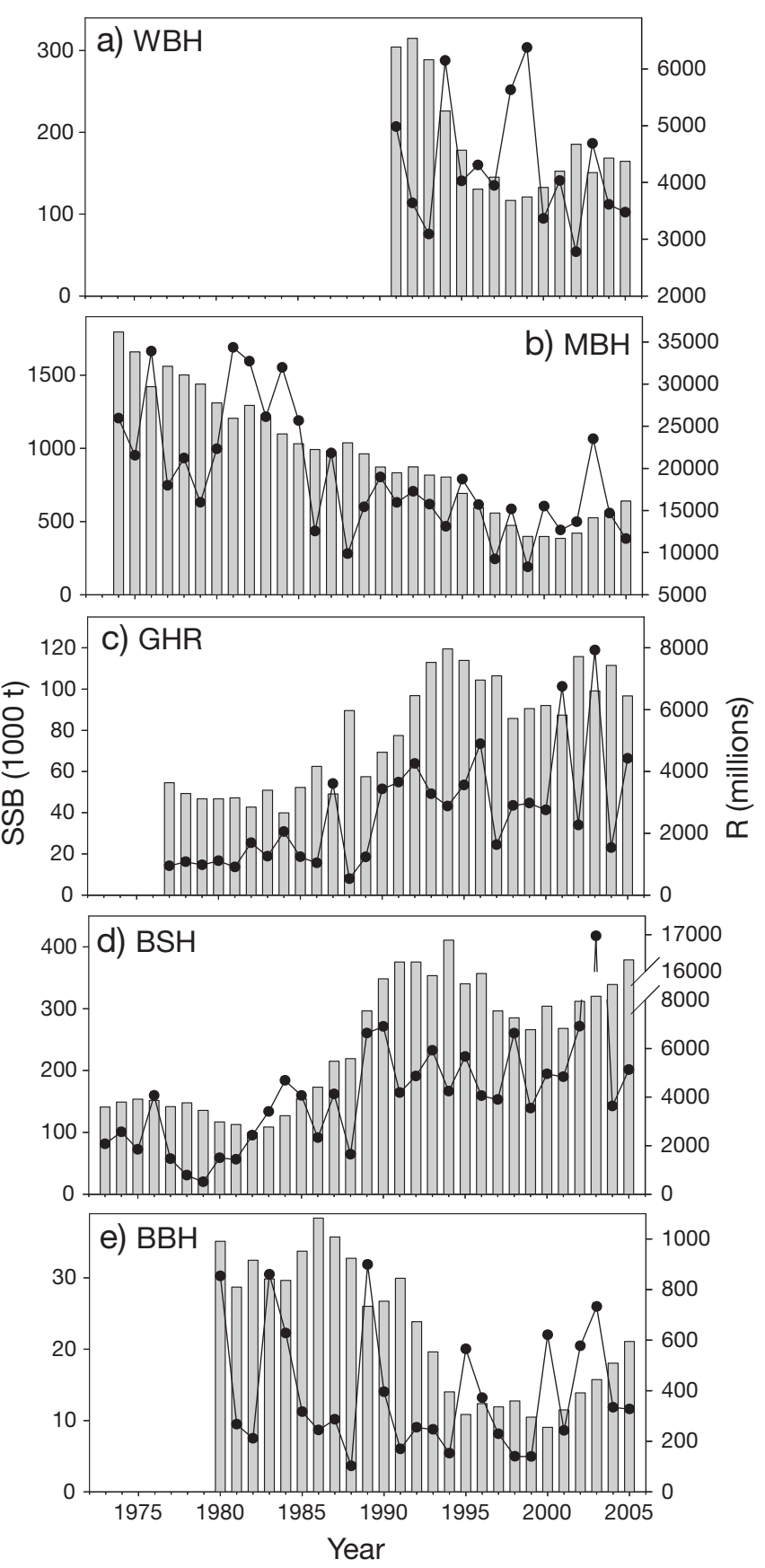

Fig. 2. Clupea harengus. Time trends of spawning stock biomass (SSB, bars) and recruitment ( $\mathrm{R}$, lines) of the different Baltic Sea herring stocks: (a) Western Baltic (WBH), (b) Central Baltic (MBH), (c) Gulf of Riga (GRH), (d) Bothnian Sea (BSH) and (e) Bothnian Bay (BBH). 
peratures in the most northerly areas, i.e. the Bothnian Sea and Bothnian Bay, have been relatively stable throughout the observed period (Fig. 4d). Deep-water salinity in the Main Basin declined until 1993 and increased afterwards (Fig. 4b). Surface salinity in the Western Baltic remained constant during the short assessment period for WBH.

The copepod spring community in the Main Basin switched from a dominance of Pseudocalanus acuspes to a dominance of Acartia spp. and Temora longicornis (Fig. 4e). The dominant copepods in the Gulf of Riga, i.e. Acartia spp. and Eurythemora affinis, have, on average, increased in spring since the early 1990s (Fig. 4f), while these species did not show any clear trend in the Bothnian Sea and in the Bothnian Bay
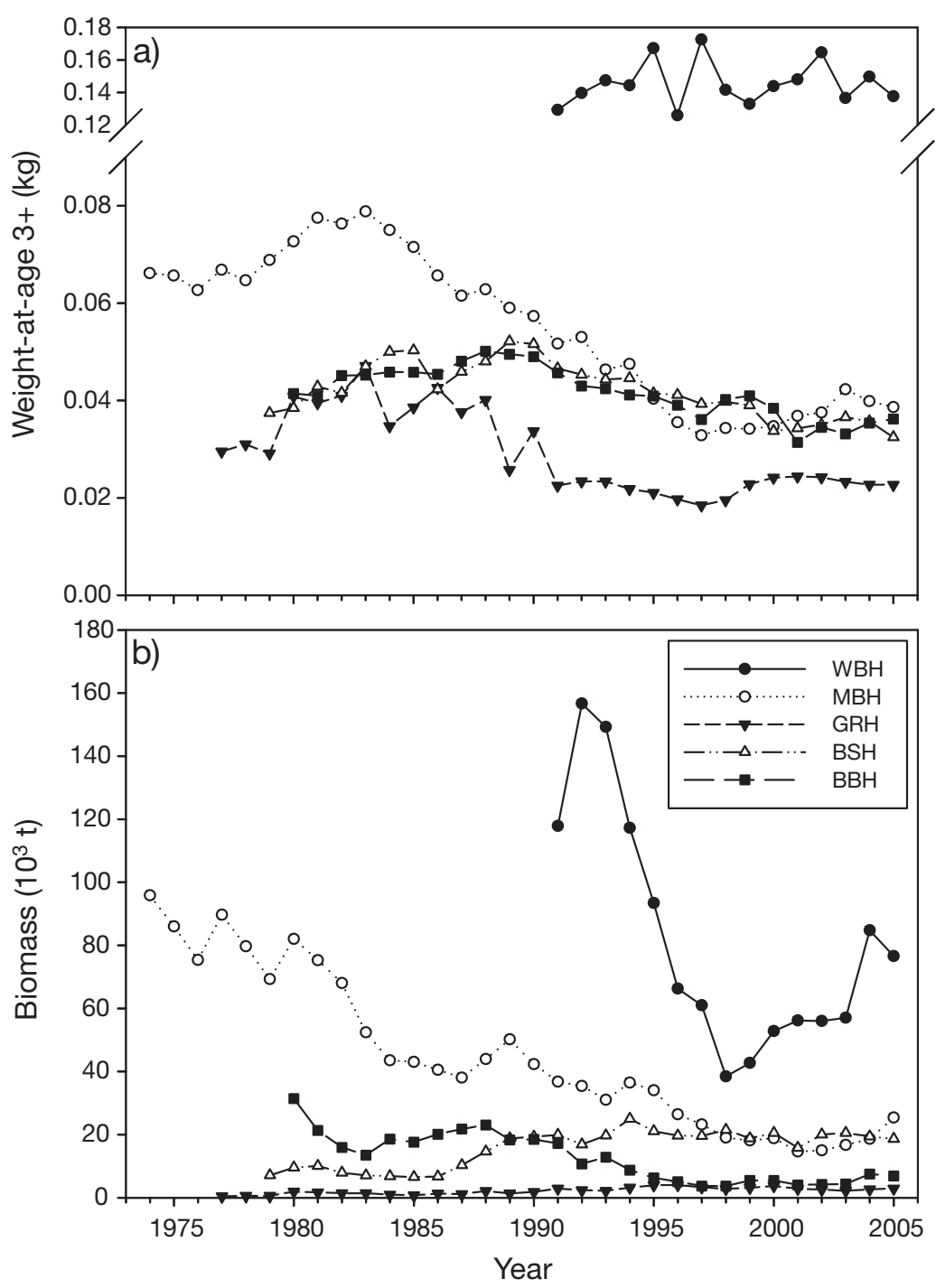

Fig. 3. Clupea harengus. Time trend in (a) weight at age of $3+y \mathrm{r}$ old fish (2+ for GRH) and (b) biomass of 5+ yr old fish for each Baltic herring stock; Western Baltic (WBH), Central Baltic (MBH), Gulf of Riga (GRH), Bothnian Sea (BSH) and Bothnian Bay (BBH)
(Fig. 4g,h). The dominant cladoceran Bosmina longispina generally increased in the Bothnian Sea with the highest biomass observed in 2002 (Fig. 4g). Predation mortality exerted by cod in the Main Basin decreased in concomitance with the decline of cod biomass (data not shown).

\section{Statistical analysis}

Results of the final models with the lowest GCV, the proportion of deviance explained by the model, the predictors explaining the largest amount of final model deviance (LED) and details of our statistical analyses, i.e. all models investigated for each stock, are given in

Table 3. Diagnostic plots of the final models are presented in Figs. 5 to 9. Analyses of the residuals of the final models indicated no violation of the normality and homogeneity assumptions and residuals were not autocorrelated at any lag. The lack of anomalies as evidenced by the model diagnostics indicates the adequacy of the models.

Temperature was detected to be a significant predictor for GRH and BSH, with warm spring associated with large year classes. In contrast to temperature, no significant effect of salinity on recruitment was detected in any of the Baltic herring stocks.

Significant effects of the condition of spawners $\left(\mathrm{WAA}_{3+}\right.$ ) and SSB were found for $\mathrm{MBH}$ and GRH, respectively (Table 2). For $\mathrm{WBH}$, the $\mathrm{WAA}_{3+}$ was eliminated by the ecological criterion as it showed a significant negative effect on recruitment (i.e. larger $\mathrm{WAA}_{3+}$ was associated with decreased R). This was considered to be a spurious correlation, as in theory fish with higher weight should produce more eggs. The same did not apply for $\mathrm{MBH}$, as for this stock a significant positive effect of $\mathrm{WAA}_{3+}$ was observed. No significant effect of the spawners was observed for the remaining 3 Baltic herring stocks. For $\mathrm{MBH}$, the interaction between $\mathrm{WAA}_{3+}$ and summer SST was the most important explanatory variable and the model with the interaction was chosen as the best model where the effect of $\mathrm{WAA}_{3+}$ is maximised at high temperature. On the other hand, for GRH the additive model with SSB and spring SST was found to be the best model to describe recruitment variation. For this stock, large year classes depend on large SSB and high temperature, although SSB explained the largest part of the model deviance. 

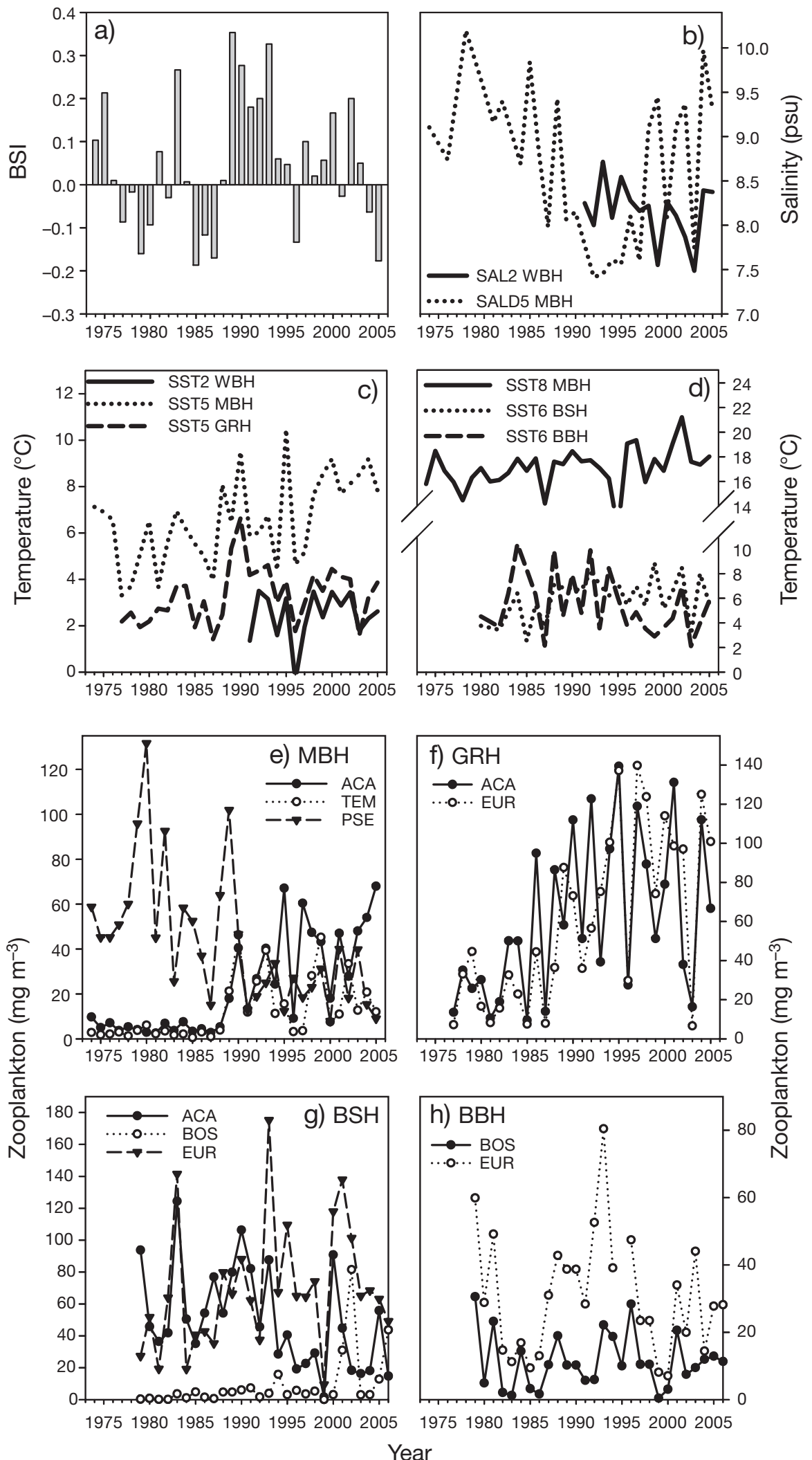

Fig. 4. Time trend of the predictors used in the analysis: (a) Baltic Sea Index (BSI), (b) salinity, (c,d) sea temperature, (e-h) zooplankton (see 'Materials and methods' for details). Pseudocalanus acuspes (PSE); Acartia spp. (ACA), Temora longicornis (TEM); Eurytemora affinis (EUR); Bosmina longispina (BOS); see Table 1 for further abbreviations 
Table 3. Clupea harengus. Details of the models tested ( $\mathrm{R}$ is number of 0 or $1 \mathrm{yr}$ old fish, depending on the stock) for each stock with generalized cross validation (GCV), total deviance explained (DEV; in percent of the model null deviance), the factors explaining the largest part of the deviance (LED) and the number of observations (n). Final (in bold) is the best model that fulfills the significance, ecological and the parsimonious criteria at the same time; significance level of the predictors is indicated only for the 2 best models. Western Baltic (WBH), Central Baltic (MBH), Gulf of Riga (GRH), Bothnian Sea (BSH) and Bothnian Bay (BBH). See Table 2 for acronym definitions

\begin{tabular}{|c|c|c|c|c|c|c|}
\hline Stock & Model & Predictors & GCV & DEV & LED & $\mathrm{n}$ \\
\hline \multirow[t]{5}{*}{ WBH } & Initial & $R \approx \mathrm{SSB}+\mathrm{WAA}_{3+}+\mathrm{SAL}_{\mathrm{Feb}}+\mathrm{BSI}+\mathrm{SST}_{\mathrm{Feb}}$ & 0.077 & 59.2 & & \\
\hline & 1 & $R \approx \mathrm{SSB}+\mathrm{WAA}_{3+}+\mathrm{SST}_{\mathrm{Feb}}+\mathrm{BSI}$ & 0.062 & 59.2 & & \\
\hline & 2 & $R \approx \mathrm{WAA}_{3+}{ }^{\mathrm{T}}+\mathrm{SST}_{\mathrm{Feb}}{ }^{\mathrm{ns}}+\mathrm{BSI}$ & 0.051 & 59.4 & & \\
\hline & 3 & $R \approx \mathrm{WAA}_{3+}+\mathrm{BSI}^{\mathrm{ns}}$ & 0.046 & 56.4 & & \\
\hline & Final & $R \approx \mathrm{BSI}^{\mathrm{ns}}$ & 0.060 & 33.6 & BSI & 15 \\
\hline \multirow[t]{7}{*}{$\mathrm{MBH}$} & Initial & $\begin{array}{l}R \approx \mathrm{SSB}+\mathrm{WAA}_{3+}+\mathrm{TEM}+\mathrm{BSI}+\mathrm{SST}_{\mathrm{May}}+ \\
\mathrm{SST}_{\mathrm{Aug}}+\mathrm{PSE}+\mathrm{SALD}\end{array}$ & 0.064 & 82.8 & & \\
\hline & 1 & $R \approx \mathrm{SSB}+\mathrm{WAA}_{3+}+\mathrm{BSI}+\mathrm{SST}_{\mathrm{May}}+\mathrm{SST}_{\mathrm{Aug}}+\mathrm{PSE}+\mathrm{SALD}$ & 0.058 & 82.9 & & \\
\hline & 2 & $R \approx \mathrm{SSB}+\mathrm{WAA}_{3+}+\mathrm{BSI}+\mathrm{SST}_{\mathrm{May}}+\mathrm{SST}_{\mathrm{Aug}}+\mathrm{PSE}+\mathrm{SALD}$ & 0.056 & 83.9 & & \\
\hline & 3 & $R \approx \mathrm{SSB}+\mathrm{WAA}_{3+}+\mathrm{BSI}+\mathrm{SST}_{\mathrm{May}}+\mathrm{SST}_{\mathrm{Aug}}+\mathrm{PSE}$ & 0.053 & 83.4 & & \\
\hline & 4 & $R \approx \mathrm{SSB}^{\mathrm{ns}}+\mathrm{WAA}_{3+}+\mathrm{BSI}+\mathrm{SST}_{\mathrm{Aug}}+\mathrm{PSE}$ & 0.048 & 81.9 & & \\
\hline & 5 & $R \approx \mathrm{WAA}_{3+}{ }^{* * *}+\mathrm{BSI}^{* *}+\mathrm{SST}_{\mathrm{Aug}}{ }^{*}+\mathrm{PSE}^{*}$ & 0.055 & 73.4 & & \\
\hline & Final & $R \approx \mathrm{BSI}^{* * *}+\mathrm{PSE}^{* *}+\mathrm{WAA}_{3+} \times \mathrm{SST}_{\mathrm{Aug}}{ }^{* * *}$ & 0.041 & 92.3 & $\mathrm{WAA}_{3+}: \mathrm{SST}_{\mathrm{Aug}}$ & 31 \\
\hline \multirow[t]{4}{*}{ GRH } & 1 & $R \approx \mathrm{SSB}+\mathrm{WAA}_{2+}{ }^{\mathrm{ns}}+\mathrm{EUR}+\mathrm{SST}_{\mathrm{May}}$ & 0.135 & 79.4 & & \\
\hline & 2 & $R \approx \mathrm{SSB}+\mathrm{EUR}+\mathrm{SST}_{\text {May }}$ & 0.126 & 79.1 & & \\
\hline & Final & $R \approx \mathrm{SSB}^{* * *}+\mathrm{SST}_{\text {May }}^{* * *}$ & 0.118 & 78.8 & SSB & 28 \\
\hline & 4 & $R \approx \mathrm{SSB} \times \mathrm{SST}_{\mathrm{May}}^{* * *}$ & 0.136 & 78.3 & & \\
\hline \multirow[t]{6}{*}{$\mathrm{BSH}$} & Initial & $R \approx \mathrm{SSB}+\mathrm{WAA}_{3+}+\mathrm{BSI}+\mathrm{SST}_{\text {June }}+\mathrm{ACA}+\mathrm{BOS}+\mathrm{EUR}$ & 0.086 & 86.6 & & \\
\hline & 1 & $R \approx \mathrm{SSB}+\mathrm{BSI}+\mathrm{SST}_{\text {June }}+\mathrm{ACA}+\mathrm{BOS}+\mathrm{EUR}$ & 0.078 & 86.7 & & \\
\hline & 2 & $R \approx \mathrm{BSI}+\mathrm{SST}_{\text {June }}+\mathrm{ACA}+\mathrm{BOS}+\mathrm{EUR}$ & 0.077 & 84.7 & & \\
\hline & 3 & $R \approx \mathrm{BSI}+\mathrm{SST}_{\text {June }}+\mathrm{ACA}^{\mathrm{ns}}+\mathrm{BOS}$ & 0.076 & 83.1 & & \\
\hline & Final & 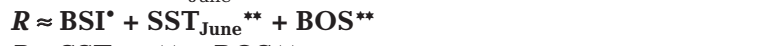 & 0.079 & 80.5 & $\mathbf{S S T}_{\text {June }}$ & 26 \\
\hline & 5 & 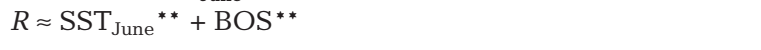 & 0.091 & 60.9 & & \\
\hline \multirow[t]{6}{*}{ BBH } & Initial & $R \approx \mathrm{SSB}+\mathrm{WAA}_{3+}+\mathrm{BSI}+\mathrm{SST}_{\text {June }}+\mathrm{BOS}+\mathrm{EUR}$ & 0.456 & 49.1 & & \\
\hline & 1 & $R \approx \mathrm{WAA}_{3+}+\mathrm{BSI}+\mathrm{SST}_{\text {June }}+\mathrm{BOS}+\mathrm{EUR}$ & 0.403 & 49.2 & & \\
\hline & 2 & $R \approx \mathrm{WAA}_{3+}+\mathrm{BSI}+\mathrm{SST}_{\text {June }}+\mathrm{BOS}$ & 0.366 & 48.5 & & \\
\hline & 3 & $R \approx \mathrm{WAA}_{3+}+\mathrm{BSI}+\mathrm{BOS}^{\mathrm{ns}}$ & 0.368 & 42.5 & & \\
\hline & 4 & $R \approx \mathrm{WAA}_{3+}{ }^{\mathrm{ns}}+\mathrm{BSI}$ & 0.403 & 19.6 & & \\
\hline & Final & $R \approx \mathrm{BSI} \mathrm{ns}^{\mathrm{n}}$ & 0.386 & 10.6 & BSI & 25 \\
\hline
\end{tabular}
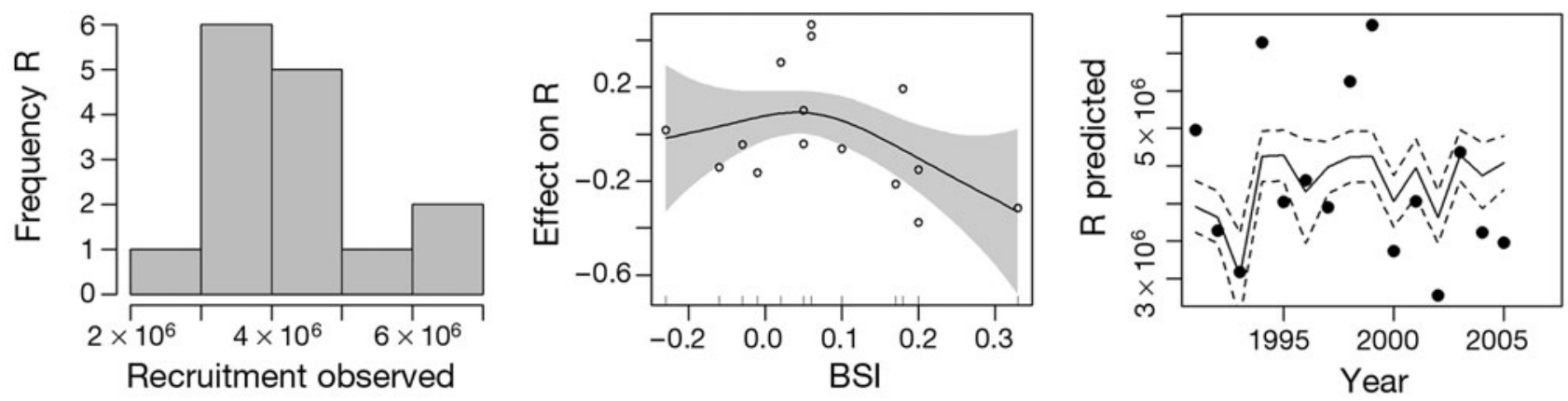

Fig. 5. Clupea harengus. Results of the recruitment analysis: frequency distribution of the response (recruitment), effect of each selected predictor on the response in the final model and predicted recruitment for Western Baltic herring (WBH). 


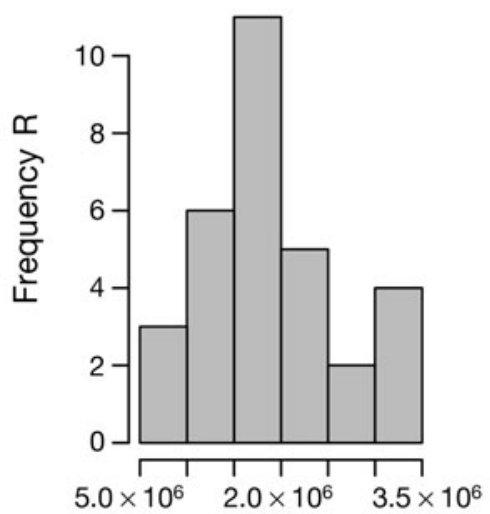

Recruitment observed
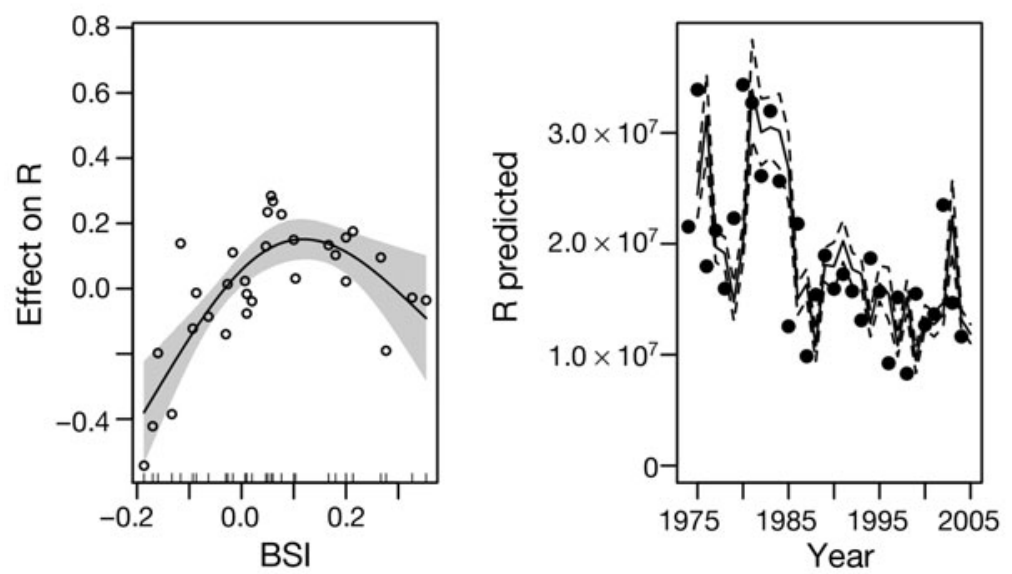

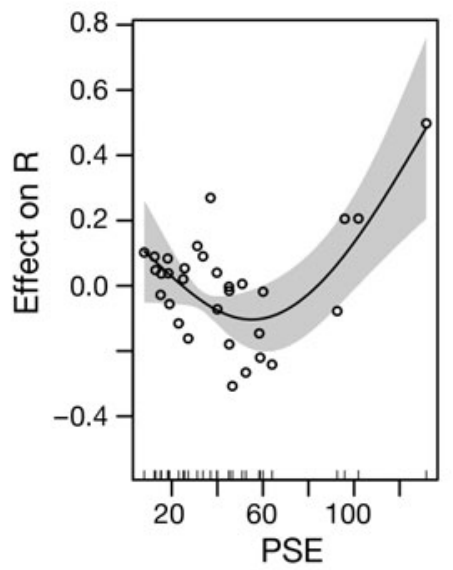

Fig. 6. Clupea harengus. Results of the recruitment analysis: frequency distribution of the response (recruitment), effect of each selected predictor on the response in the final model and predicted recruitment forCentral Baltic herring $(\mathrm{MBH})$. See Table 2 for acronym definitions
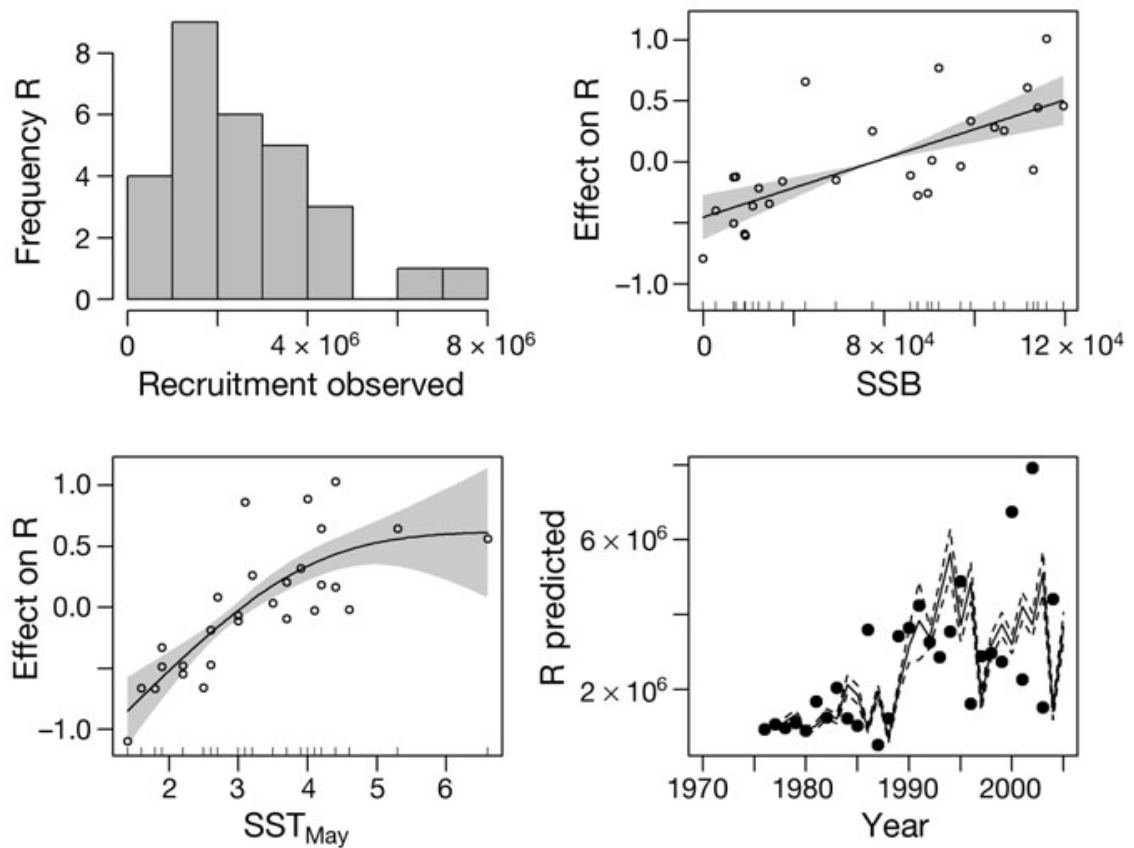

Fig. 7. Clupea harengus. Results of the recruitment analysis: frequency distribution of the response (recruitment), effect of each selected predictor on the response in the final model and predicted recruitment for Gulf of Riga herring (GRH). See Table 2 for acronym definitions 

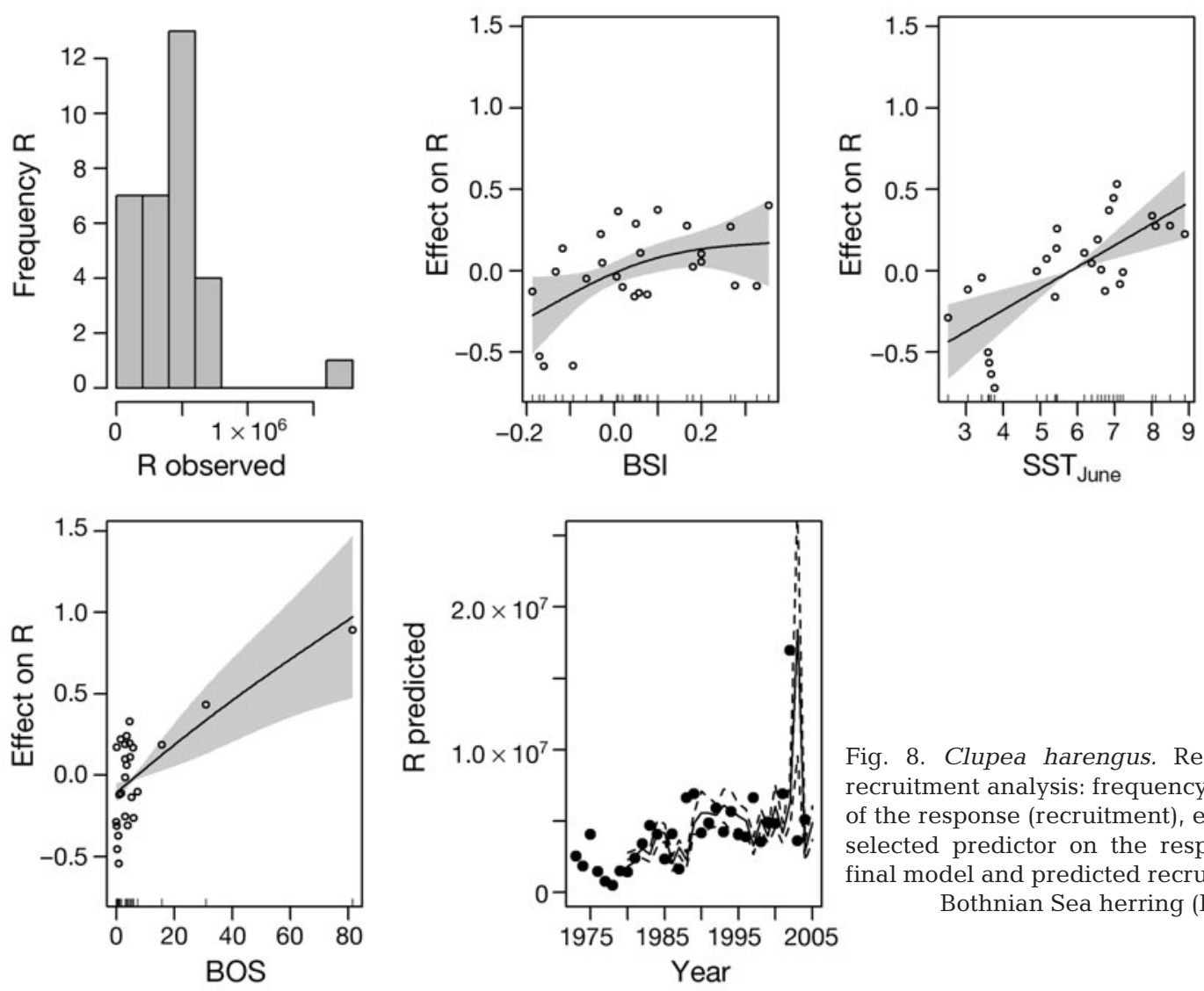

Fig. 8. Clupea harengus. Results of the recruitment analysis: frequency distribution of the response (recruitment), effect of each selected predictor on the response in the final model and predicted recruitment for Bothnian Sea herring (BSH)
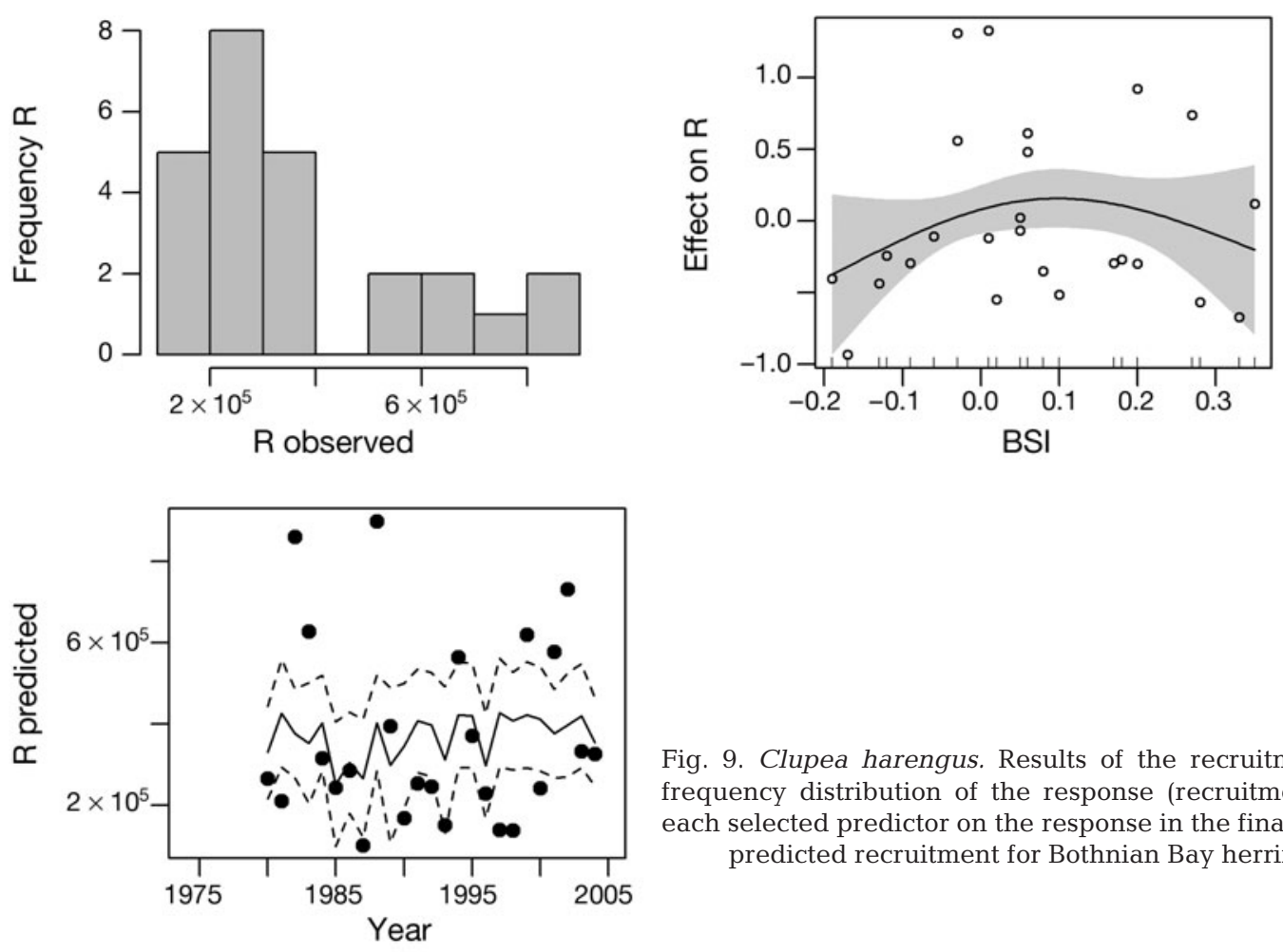

Fig. 9. Clupea harengus. Results of the recruitment analysis: frequency distribution of the response (recruitment), effect of each selected predictor on the response in the final model and predicted recruitment for Bothnian Bay herring $(\mathrm{BBH})$ 
For MBH and BSH stocks, food supply (i.e. zooplankton prey density) was a significant recruitment predictor (Pseudocalanus acuspes and Bosmina longispina, respectively). For BBH, Bosmina longispina was excluded by the ecological criterion as it showed a significant negative effect on recruitment (i.e. larger biomass of Bosmina longispina was associated with decreased R). This was considered to be a spurious correlation, as in theory large abundance of the prey species Bosmina longispina should favour herring larvae survival. The same did not apply for $\mathrm{BSH}_{\text {, as for }}$ this stock a significant positive effect of Bosmina longispina was observed.

All predictors selected in the final models were significant at $5 \%$ except BSI in BSH $(p=0.08)$. For WBH and $\mathrm{BBH}$, no satisfactory model was found, as the final predictor (i.e. BSI for both stocks) was not significant ( $p>0.1$ ). In our data, moderate significant temporal autocorrelation ( $\mathrm{r}=0.45$ to 0.54 ) in the response variable (recruitment) was present in 3 out of 5 stocks analysed (MBH and BSH at Lag 1, GRH at Lag 2). However, autocorrelation for this model was moderate and thus most likely did not affect the final results. However, it is also worth noting that temporal autocorrelation is an inside feature of many ecological time series and that removing autocorrelation might decrease the potential to detect crucial ecological processes.

\section{DISCUSSION}

Small pelagic fishes such as herring react strongly and quickly to climate change due to their tight links to environmental forcing, which affects key processes such as distribution, growth, spawning and feeding (Rose 2005). There are several examples showing that the inclusion of temperature in stock-recruitment models increases prediction abilities, as for Norwegian spring spawning herring (Fiksen \& Slotte 2002) and for the Pacific herring in the Bering Sea and northeast Pacific Ocean (Williams \& Quinn 2000). Beside the influence of climate, a part of the observed variability around the relationship between SSB and fish recruitment might depend on other factors, such as stock structure (i.e. maternal effect, Marshall et al. 1998), or changes in fecundity and condition of the spawners (Olsen et al. 2004, Scott et al. 2006).

Using GAMs we statistically investigated Baltic herring recruitment-environment relationships during a period of prominent change in atmospheric forcing. Two of the main underlying assumptions of GAMs are that the functions are additive and that the components are smooth (Hastie \& Tibshirani, 1990). Through the use of smoothing functions a GAM implicitly as- sumes the existence of smoothed non-linearity in the relationship between the mean of the response variable and the predictors (Hastie \& Tibshirani 1990). Applying GAMs to time-series analysis we essentially take into account part of the temporal structure of the included covariates, making a not-explicit treatment of the autocorrelation in the predictors probably less problematic than with linear models. Due to this ability to deal with high non-linear and non-monotonic relationships between the response and the set of predictors, GAMs were sometimes referred to as a data- rather than a model-driven approach (Guisan et al. 2002).

By comparing the 5 different Baltic herring stocks, we found temperature to be a parameter contributing to recruitment for 3 stocks ( $\mathrm{MBH}, \mathrm{GRH}$ and BSH). For these stocks, temperature was positively correlated with recruitment, i.e. larger year classes were found in years of higher temperature. The BSI (climate index related to temperature) was selected in the final model of the other 2 stocks, but it was not significant. When condition of spawners $\left(\mathrm{WAA}_{3+}\right)$ or SSB was selected in the models (i.e. for $\mathrm{MBH}$ and GRH stocks, respectively), these characteristics of the spawning fish were the most important predictors in explaining recruitment. This emphasizes the occurrence of spatial differences in the main regulation mechanisms of herring recruitment in the Baltic Sea.

A number of processes can explain the positive relationship between temperature and Baltic herring recruitment. Higher temperature may affect adult fecundity and egg production and shorten the incubation period, decreasing the predation risk at the egg stage (Rajasilta et al. 1993). Moreover, higher temperatures can be favourable for herring larval survival either directly, acting on metabolism and growth rates (Hakala et al. 2003), or indirectly, promoting rich primary production in the period of larval development (Parmanne \& Sjöblom 1982). Ottersen \& Loeng (2000) also suggested that high temperatures caused increased prey production in the Barents Sea, which led to higher growth rates and higher survival through the vulnerable larval and juvenile stages. Mikkelsen \& Pedersen (2004) showed that capelin recruitment in the Barents Sea is positively correlated with higher water temperatures, whereas Stocker et al. (1985) found a dome-shaped relationship between temperature and spawning success with an optimal temperature during larval stages resulting in maximum production of recruits in the Strait of Georgia. Several field and experimental studies have shown that Baltic herring egg mortality may increase for very high values of water temperature that can cause abnormalities to the embryos and larvae (Raid 1991), inhibit herring spawning (Parmanne et al. 1997 and references 
therein), and increase the risk of bacterial and fungal infections (Rajasilta et al. 1993). These mechanisms could explain the dome-shaped relations between recruitment and BSI, and between recruitment and $\mathrm{SST}$, in $\mathrm{MBH}$ and $\mathrm{GRH}$, respectively.

Our results further showed that in the areas where zooplankton time-series were available, zooplankton was a significant predictor for Baltic herring recruitment in 2 out of 4 stocks. Numerous studies have documented the sensitivity of zooplankton to climate variability (e.g. Fromentin \& Planque 1996, Beaugrand et al. 2002, Möllmann et al. 2000), and a number of investigations have demonstrated the importance of these changes in food availability for fish stocks (e.g. Beaugrand et al. 2003).

For Baltic fish stocks, the effect of zooplankton has been demonstrated for cod and sprat recruitment (Köster et al. 2005, Möllmann et al. 2008). In our study, the findings by Kornilovs (1993), that showed the copepod Eurytemora affinis to be important for recruitment success of GRH, were not directly confirmed. However, this copepod species experienced temperaturedriven increases in population size during the study period and therefore the exclusion of $E$. affinis from the final model is likely due to collinearity $\left(\mathrm{r}^{2}=0.36\right.$; $\mathrm{p}<$ 0.05 ) with SST, as the GCV was used to select final predictors. Thus, we argue that high temperature and large abundance of $E$. affinis are tightly interconnected and they have likely supported the high GRH recruitment level since the 1990s. Positive effects of sufficient amount of food and increased temperatures were also confirmed by laboratory experiments with Norwegian spring-spawning herring larvae (Fiksen \& Folkvord, 1999). Food availability was found to be a significant predictor for MBH recruitment as shown by the significant effect of the copepod Pseudocalanus acuspes. Möllmann et al. (2008) and Casini et al. (2009) showed that $P$. acuspes stock decreased during the study period due to a drop in salinity and increased predation by an enlarged sprat stock. Since $P$. acuspes mainly occurs in the high-saline deep waters of the Baltic main basins and herring spawn in shallow waters, it is likely that $P$. acuspes acts indirectly on herring recruitment via affecting the body growth of the parental stock, as indicated by the significant effect of $\mathrm{WAA}_{3+}$ in the model (see below). Unfortunately, no sufficiently long zooplankton time series were available for $\mathrm{WBH}$ and we could not investigate the zooplankton effect on herring recruitment for this stock.

Besides the influence of climate (i.e. temperature) on Baltic herring recruitment, our analyses indicate an effect of SSB (i.e. a proxy for egg production) on recruitment for GRH, which is partially different from the results of Cardinale et al. (2008), who found this relationship also for $\mathrm{WBH}, \mathrm{MBH}$ and $\mathrm{BBH}$. The apparent difference in the results of the 2 studies is due to the use of recruitment instead of recruitment success as response variable, but also to the larger set of predictors used in our study. Furthermore, for $\mathrm{MBH}$, the condition of the spawners $\left(\mathrm{WAA}_{3+}\right)$ was the most important explanatory variable of recruitment and condition is also considered as a proxy for egg production of the stock (Laine \& Rajasilta 1999), thus partially confirming the results of Cardinale et al. (2008) for this stock. In fact, field and experimental studies performed in the Archipelago Sea by Laine \& Rajasilta (1999) demonstrated that larger fish, which are in a better condition and hence have a higher fat content, have larger gonads before spawning and produce eggs with a better survival and hatching success. Our study confirms these observations, showing that $\mathrm{WAA}_{3+}$ has a positive impact on recruitment of $\mathrm{MBH}$. Growth and condition of MBH individuals have declined drastically in recent decades due to lower salinity conditions and strong competition with the increased sprat stock (Cardinale \& Arrhenius 2000, Möllmann et al. 2005, Casini et al. 2006). The low body condition $\left(\mathrm{WAA}_{3+}\right)$ of $\mathrm{MBH}$ spawners may have negatively influenced the quantity and quality of the offspring and hence the year-class strength. It is also important to note that the interaction between temperature and $\mathrm{WAA}_{3+}$ was the most important predictor for this stock. The shape of this interaction supports the hypothesis that a combination of high temperature and high $\mathrm{WAA}_{3_{+}}$is necessary to produce very large year classes in $\mathrm{MBH}$.

Since the number of recruits in a fish species is generally related to egg number (Myers \& Barrowman 1996), one might argue that SSB should always be included when predicting recruitment. In particular cases, i.e. where the time series is relatively short, the range in SSB is small or the SSB time series do not include values close to the origin, we might run the risk of erroneously excluding SSB on the basis of the parsimonious principle. As a matter of fact, recruitment is obviously impaired when SSB approaches the origin. Nevertheless, while SSB should be always included in recruitment models used for short-term predictions (see also ICES 2008 for a useful discussion), the purposes of our analysis were to investigate if and how different predictors affect recruitment dynamics of herring in the Baltic Sea; this is because our final models were based on ecological and parsimonious criteria only.

Of the 4 Baltic herring stocks with assessment periods of more than $20 \mathrm{yr}$, SSB of MBH and BBH declined, while GRH and BSH increased. The latter 2 clearly profited from the warming conditions, especially during the early 1990s, which resulted in increased 
year-class strength and eventually larger biomasses. By contrast, the stock of BBH declined since the early 1990s and no consistent positive trend in recruitment has been observed. For BBH, spawning occurs in June and warmer conditions favour recruitment success (ICES 2008), however no clear warming trend occurred in this area. For $\mathrm{MBH}$, fishing pressure was considered unsustainable in the 1990s and contributed, together with low $\mathrm{WAA}_{3+}$ (see Fig. 6), to the decline of the recruitment and in turn of the stock (ICES 2007). Recruitment of this stock might also indirectly depend on the salinity- and predation-regulated abundance of the copepod Pseudocalanus acuspes (Möllmann et al. 2003, Casini et al. 2009) acting on spawners' growth.

In summary, this study underlines the regional variability of the main factors driving herring recruitment throughout the Baltic Sea. Temperature is clearly influencing herring recruitment in $\mathrm{MBH}$, GRH and $\mathrm{BSH}$, likely acting to a large degree by changing the zooplankton food supply and thus larval survival. However, the parental stock characteristics (weight-atage of spawners and spawning biomass) also play a crucial role in the Baltic Sea, being the major regulator in the recruitment dynamics of MBH and GRH stocks, respectively. Our results point to the importance of considering area-specific differences in herring recruitment dynamics in the management of the different stocks in the Baltic Sea. For instance, managers should use an adaptive strategy to cope with changes in temperature. Also, a management targeting high SSB (for GRH) or low competition with sprat (for MBH) could also help maintain good recruitment potentials for the stocks inhabiting the central areas. Moreover, our results confirm the importance of (1) long-term zooplankton monitoring for evaluating the effects of climate change on marine ecosystems and predicting recruitment for management purposes, and (2) the need of a better understanding of biological process to validate the results of statistical recruitment studies like those conducted here.

Acknowledgements. We thank Dr. J. Lasinio for useful advice on temporal autocorrelation in GAM analysis. We also thank 3 anonymous referees for their especially useful suggestions that greatly improved the first version of the paper.

\section{LITERATURE CITED}

Alheit J, Möllmann C, Dutz J, Kornilovs G, Löwe P, Mohrholz V, Wasmund N (2005) Synchronous ecological regime shifts in the North and Central Baltic Sea in 1987-88. ICES J Mar Sci 62:1205-1215

Aro E (1989) A review of fish migration patterns in the Baltic. Rapp P-V Réun Cons Int Explor Mer 190:72-96
Beaugrand G, Reid PC, Ibañez F, Lindley JA, Edwards M (2002) Reorganization of North Atlantic marine copepod biodiversity and climate. Science 296:1692-1694

Beaugrand G, Brander KM, Lindley JA, Souissi S, Reid PC (2003) Plankton effect on cod recruitment in the North Sea. Nature 426:661-664

Blaxter JHS, Hunter JR (1982) The biology of clupeoid fishes. Academic Press, New York

Brockwell PJ, Davis RA (1996) Introduction to time series and forecasting. Springer, New York

> Cardinale M, Arrhenius F (2000) Decreasing in weight-at-age of Baltic herring (Clupea harengus) between 1986 and 1996: a statistical analysis. ICES J Mar Sci 57:882-893

> Cardinale M, Svedäng H (2004) Modelling recruitment and abundance of Atlantic cod, Gadus morhua, in the Kattegat-eastern Skagerrak (North Sea): evidence of severe depletion due to a prolonged period of high fishing pressure. Fish Res 69:263-282

Cardinale M, Hjelm J, Casini M (2008) Disentangling the effect of adult biomass and temperature on recruitment dynamic of fishes. Cod and Climate, Alaska Sea Grant College Program, AK-SG-08-01:221-237

> Casini M, Cardinale M, Hjelm J (2006) Inter-annual variation in herring, Clupea harengus, and sprat, Sprattus sprattus, condition in the central Baltic Sea: what gives the tune? Oikos 112:638-650

Casini M, Lövgren J, Hjelm J, Cardinale M, Molinero JC, Kornilovs G (2008) Multi-level trophic cascades in a heavily exploited open marine ecosystem. Proc R Soc Lond B Biol Sci 275:1793-1801

Casini M, Hjelm J, Molinero JC, Lövgren J and others (2009) Trophic cascades promote threshold-like shifts in pelagic marine ecosystems. Proc Natl Acad Sci USA 106:197-202

Cleveland WS (1993) Visualizing data. Hobart Press, Summit, NJ

Dippner J, Ottersen G (2001) Cod and climate variability in the Barents Sea. Clim Res 17:73-82

Fiksen Ø, Folkvord A (1999) Modelling growth and ingestion processes in herring Clupea harengus larvae. Mar Ecol Prog Ser 184:273-289

> Fiksen Ø, Slotte A (2002) Stock-environment recruitment models for Norwegian spring spawning herring (Clupea harengus). Can J Fish Aquat Sci 59:211-217

Fromentin JM, Planque B (1996) Calanus and environment in the eastern North Atlantic. II. Influence of the North Atlantic Oscillation on C. finmarchicus and C. helgolandicus. Mar Ecol Prog Ser 134:111-118

> Guisan A, Edwards TC, Hastie T Jr (2002) Generalized linear and generalized additive models in studies of species distributions: setting the scene. Ecol Model 157:89-100

Hakala T, Viitasalo M, Rita H, Aro E, Flinkman J, Vuorinen I (2003) Temporal and spatial variation in the growth rates of Baltic herring (Clupea harengus membras L.) larvae during summer. Mar Biol 142:25-33

Hastie T, Tibshirani R (1990) Generalized additive models. Chapman and Hall, London

> Heinänen S, Rönkä M, von Numers M (2008) Modelling the occurrence and abundance of a colonial species, the arctic tern Sterna paradisaea in the archipelago of SW Finland. Ecography 31:601-611

> Hurrell JW (1995) Decadal trends in the North Atlantic Oscillation: regional temperatures and precipitation. Science 269:676-679

ICES (2006a) Report of the Herring Assessment Working Group South of $62^{\circ}$ N. ICES CM 2006/ACFM:20

ICES (2006b) Report of the Baltic Fisheries Assessment Working Group. ICES CM 2006/ACFM:24 
ICES (2007) Report of the ICES Advisory Committee on Fishery Management, Advisory Committee on the Marine Environment and Advisory Committee on Ecosystems, 2007. ICES Advice. Books 1-10:6, 310 pp.

ICES (2008) Report on developing and testing environmentally-sensitive stock-recruitment relationships of Baltic herring and sprat stocks. ICES CM 2008/BCC:05

Kornilovs G (1993) The modern state of Baltic herring spawning grounds in the Gulf of Riga. ICES CM 1993/J:26

Kornilovs G, Sidrevics L, Dippner JW (2001) Fish and zooplankton interaction in the Central Baltic Sea. ICES J Mar Sci 58:579-588

Köster FW, Hinrichsen HH, Schnack D, St. John MA and others (2003) Recruitment of Baltic cod and sprat stocks: identification of critical life stages and incorporation of environmental variability into stock-recruitment relationships. Sci Mar 67:129-154

Köster FW, Möllmann C, Hinrichsen HH, Tomkiewicz J and others (2005) Baltic cod recruitment - the impact of climate and species interaction. ICES J Mar Sci 62:1408-1425

Laine P, Rajasilta M (1999) The hatching success of Baltic herring eggs and its relation to female condition. J Exp Mar Biol Ecol 237:61-73

Lehmann A, Krauss W, Hinrichsen HH (2002) Effects of remote and local atmospheric forcing on circulation and upwelling in the Baltic Sea. Tellus Ser A Dyn Meterol Oceanogr 54:299-316

Link JS, Bogstad B, Sparholt H, Lilly GR (2008) Thropic role of Atlantic cod in the ecosystem. Fish Fish 9:1-30

MacKenzie BR, Köster FW (2004) Fish production and climate: sprat in the Baltic Sea. Ecology 85:784-794

> Marshall T, Kjesbu OS, Yaragina NA, Solemdal P, Ulltang Ø (1998) Is spawner biomass a sensitive measure of the reproductive and recruitment potential of northeast arctic cod? Can J Fish Aquat Sci 55:1766-1783

Mikkelsen N, Pedersen T (2004) How can the stock recruitment relationship of the Barents Sea capelin (Mallotus villosus ) be improved by incorporating biotic and abiotic factors? Polar Res 23:19-26

Möllmann C, Kornilovs G, Sidrevics L (2000) Long-term dynamics of main mesozooplankton species in the Central Baltic Sea. J Plankton Res 22:2015-2038

Möllmann C, Kornilovs G, Fetter M, Köster FW, Hinrichsen HH (2003) The marine copepod Pseudocalanus elongatus, as a mediator between climate variability and fisheries in the Central Baltic Sea. Fish Oceanogr 12: 360-368

Möllmann C, Kornilovs G, Fetter M, Köster FW (2005) Climate, zooplankton and pelagic fish growth in the Central Baltic Sea. ICES J Mar Sci 62:1270-1280

Möllmann C, Müller-Karulis B, Kornilovs G, St. John MA (2008). Effects of climate and overfishing on zooplankton dynamics and ecosystem structure: regime shifts, trophic cascade, and feedback loops in a simple ecosystem. ICES J Mar Sci 65:302-310

Myers RA, Barrowman NJ (1996) Is fish recruitment related to spawning abundance? Fish Bull 9:707-724

Editorial responsibility: Andrew Brierley, St. Andrews, UK
O'Brien CM, Fox CJ, Planque B, Casey J (2000) Climate variability and North Sea cod. Nature 404:142

Olsen EM, Heino M, Lilly GR, Morgan MJ, Brattey J, Ernande B, Dieckmann U (2004) Maturation trends indicative of rapid evolution preceded the collapse of northern cod. Nature 428:932-935

> Ottersen G, Loeng H (2000) Covariability in early growth and year-class strength of Barents Sea cod, haddock, and herring: the environmental link. ICES J Mar Sci 57:339-348

Parmanne R, Sjöblom V (1982) Abundance, mortality and production of spring-spawning Baltic herring larvae in the seas around Finland in 1979. Finn Fish Res 6:15-19

Parmanne R, Rechlin O, Sjöstrand B (1994) Status and future of herring and sprat stocks in the Baltic Sea. Dana 10: 29-59

Parmanne R, Popov A, Raid T (1997) Fishery and biology of herring (Clupea harengus L.) in the Gulf of Finland: a review. Boreal Env Res 2:217-227

Raid T (1991) Herring spawning grounds in the northeastern Baltic: recent changes and present situation. Proc Intl Herring Symp, October 1990, Anchorage, AK, p 629-638

Rajasilta M, Eklund J, Kääriä J, Ranta-Aho K (1989) The deposition and mortality of eggs of the Baltic herring, Clupea harengus membras L., on different substrates of the south-west archipelago of Finland. J Fish Biol 34:417-427

Rajasilta M, Eklund J, Hänninen J, Kurkilathi M, Kääriä J, Rannikko P, Soikkeli M (1993) Spawning of herring (Clupea harengus membras L.) in the Archipelago Sea. ICES J Mar Sci 50:233-246

Rose GA (2005) On distributional responses of North Atlantic fish to climate change. ICES J Mar Sci 62:1360-1374

Scott BE, Marteinsdottir G, Begg GA, Wright PJ, Kjesbu OS (2006) Effects of population size/age structure, condition and temporal dynamics of spawning on reproductive output in Atlantic cod (Gadus morhua). Ecol Model 191: $383-415$

Stige LC, Ottersen G, Brander K, Chan KS, Stenseth NC (2006) Cod and climate: effect of the North Atlantic Oscillation on recruitment in the North Atlantic. Mar Ecol Prog Ser 325:227-241

Stocker M, Haist V, Fournier D (1985) Environmental variation and recruitment of Pacific herring (Clupea harengus pallasi) in the Strait of Georgia. Can J Fish Aquat Sci 42(Suppl 1):174-180

Venables WN, Ripley BD (1994) Modern applied statistics with S-Plus. Springer-Verlag, New York

Williams EH, Quinn TJ II (2000) Pacific herring, Clupea pallasi, recruitment in the Bering Sea and north-east Pacific Ocean, II: relationships to environmental variables and implications for forecasting. Fish Oceanogr 9:300-315

Wood SN (2003) Thin-plate regression splines. J R Stat Soc B 65:95-114

Wood SN (2004) Stable and efficient multiple smoothing parameter estimation for generalized additive models. J Am Stat Assoc 99:673-686

Wood SN (2006) Generalized additive models. An introduction with R. Chapman \& Hall/CRC, Boca Raton, FL

Submitted: December 1, 2008; Accepted: May 25, 2009

Proofs received from author(s): July 28, 2009 